\title{
CORRECTION
}

\section{Correction to: Isolation of endophytic fungi with antimicrobial activity from medicinal plant Zanthoxylum simulans Hance}

\author{
Jimmy Kuo ${ }^{1,2} \cdot$ Chin-Feng Chang ${ }^{3} \cdot$ Wei-Chiung $\mathrm{Chi}^{4}$ \\ Published online: 11 May 2021 \\ (c) Institute of Microbiology, Academy of Sciences of the Czech Republic, v.v.i. 2021
}

\section{Correction to: Folia Microbiologica https://doi.org/10.1007/s12223-021-00854-4}

The original version of the article unfortunately contained an error.

There was a misspelling of the second author's name. The correct spelling of the second author's name is ChinFeng Chang, not Chan as printed. The correct author name is shown above.
Publisher's Note Springer Nature remains neutral with regard to jurisdictional claims in published maps and institutional affiliations.

Jimmy Kuo and Chin-Feng Chang have contributed equally to this work.

The original article can be found online at https://doi.org/10.1007/ s12223-021-00854-4.

Wei-Chiung Chi

joan@email.nqu.edu.tw

1 Department of Planning and Research, National Museum of Marine Biology and Aquarium, Pingtung 94450, Taiwan

2 Graduate Institute of Marine Biology, National Dong Hwa University, Pingtung 94450, Taiwan

3 Department of Biological Science and Technology, China University of Science and Technology, Taipei 11581, Taiwan

4 Department of Food Science, National Quemoy University, Kinmen 89250, Taiwan 